\title{
Roteiro Metodológico para Gamificação do Geodesign Aplicado ao Planejamento Urbano: Por uma Experiência Lúdica no Projeto de Futuros Alternativos para a Cidade com Crianças

\author{
Methodological Guide for the Gamification of Geodesign Applied to Urban Planning: For a \\ Ludic Experience on the Project of Alternative Futures for the City with Children
}

\author{
Bruno Amaral de Andrade \\ Universidade Federal de Minas Gerais, Brasil \\ deandradebruno@ufmg.br \\ Camila Marques Zyngier \\ Universidade Federal de Minas Gerais, Brasil \\ camilazyngier@gmail.com
}

\author{
Hilda Tellioglu \\ Universidade Técnica de Viena, Áustria \\ hilda.tellioglu@tuwien.ac.at \\ Ana Clara Mourão Moura \\ Universidade Federal de Minas Gerais, Brasil \\ anaclara@ufmg.br
}

\begin{abstract}
This article aims to present a Methodological Guide to add gamification elements to the Geodesign framework when planning the future of the city, using Geogames such Minecraft, with the participation of children in Tirol, in Brazil. The problematic tackled is related to the challenges that participants of a Geodesign workshop face when co-designing projects as alternative futures for the territory, such as losing engagement and involvement. To support the participants overcome these challenges we incorporate playfulness into the some of the Geodesign workshop phases enhancing geovisualization, collaboration and cognition.
\end{abstract}

Keywords: Geodesign; Geogames; Geovisualization; Participatory Planning; Chindren’s Design.

\section{Introduction}

This article tackles recent discussions about the application of instruments and logics of videogames towards architecture and urbanism studies. The double thematic is Participatory Planning \& Geodesign, which in the state of the art deals with the use of tools of Geographic Information Systems (GIS) (Moura, 2014) for modeling and simulating urban scenarios, and its correlation with advanced studies in Smart and Digital Communities (Banerjee and Fischer-Schreiber, 2015). This articulation of knowledge creates an opportunity for innovation in the research of methods, techniques and instruments aimed at participatory democracy in territorial planning (Paba et al., 2009).

The problem identified is related to the construction of maps and systems to run a Geodesign workshop by the technical team, but mainly the difficulties in user-computer interaction, such as the loss of engagement in certain phases of the workshop activities. Geodesign (Steinitz, 2016) is an example of a participatory design methodology directed to projecting alternative futures for the territory, using the online platform Geodesign Hub as a facilitator tool to the process. Zyngier (2016) argues in favor of Rowe and Frewer (2004, p. 548) with respect to the "what works best when" theory, in which the typologies and techniques most appropriated for public participation must be hybrid, covering also traditional methods. Therefore, this research proposes to tackle the problematic related to the difficulties faced by the participants in the Geodesign workshop, which, although it already presents a hybridization of participation techniques, there is a gap to propose gamification dynamics to face the loss of engagement in certain phases of the workshop.

The goal is to develop a method associating game technologies to Geodesign for application in urban scenarios. Therefore, a Methodological Guide is presented with the intention of incorporating ludic elements of gamification to the Geodesign workshop, through the application of the digital game Minecraft, with the participation of children between 09 and 13 years of a public school in the town of Tirol, in Brazil. It also presents "Unity" (Goldstone, 2009) as a tool for the reconstruction of the block-by-block co-design logic used in the aforementioned game, to dialog to the proposition of this gamification of geodesign research. This critical reflection of the Geodesign workshop towards gamification, refers to the incorporation of theories and practices such as engagement and fun (Poplin, 2012), geovisualization (Andrienko et al, 2007, Andrienko et al, 2011, MacEachren, 2004), and geogames (Schlieder, 2014; Schlieder et al 2005.

Regarding the challenges of the participatory Geodesign dynamics that this research intends to face, the focus is on the difficulties faced by the users (Front-end) during the workshops, which are related to 1) reading, visualizing and working with georeferenced data, maps, systems and models in the online platform; 2) interaction and consensus with other users/groups, and 3) timing control of the process of understanding and handling data and designing diagrams/projects. The methodological procedure for modeling the Minecraft geogame as a tool to gamify Geodesign, in order to face the three challenges described above, is structured and adapted from the Design Games 
phase and the Design Models of the multidisciplinary Design Thinking (mDT) (Tellioglu, 2016a; 2016b), whose centrality is involvement of users in all phases of the design process to support creativity in design and relevance of the artifact-indesign. The evaluation of the mechanical performance of the geogames will be developed according to heuristic criteria based on Schlieder (2004) and Ahlqvist et al. (2014), and participatory the performance evaluation will be developed according to Participatory Cube criteria (Poplin et al, 2013).

\section{G's: Geodesign, Geovisualization and Geogames}

The Geodesign framework (Steinitz, 2016) proposes a collaborative design of alternative futures by maximization of consensus, in successive groupings among diverse actors of society (Figure 1). It is a spinal structure based on six questions that originates six models, in which the first three refer to the Evaluation phase, and the last three to Intervention, allowing non-linear loops and specific approaches. This article focuses on the first phase of Evaluation, as a study to prepare public participation for the Geodesign workshop. In fact, the framework is a methodological process for the co-design of a territory with support of geotechnology, in order to understand potentials and impacts of the designs, in a way to be an incessant review and improvement process.

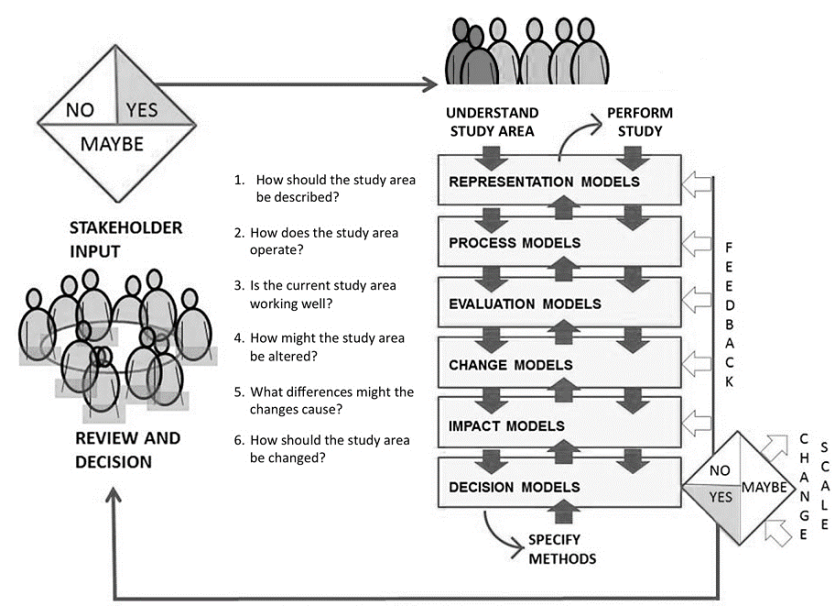

Figura 1: The framework of Geodesign (Steinitz, 2016, p.52)

The Geodesign Hub, an online platform for collaborative diagrams, is imbued with geo-visualization elements. According to MacEchren (2004), there are four major geovisualization goals: visualization to decode volume and complexity of information, towards a visual representation of knowledge; 2) Universal access and usability, towards extending the view to diverse platforms; 3) acquisition of information on mobile devices, access and use, including visualization design for small and portable wireless; and 4) collaborative work with geospatial information (including attention to the role of visual display as mediator for groups discussion on different territories). One of the main challenges identified by MacEachren (2004) is related to the practical use of geo-visualization, in terms of the difficulty of manipulating software, mainly by non-specialist users. Andrienko et al.
(2011) defend the term Geo-Visual Analysis as new approaches to solve contemporary problematic involving geographic space and its objects, events, phenomena and processes. The articulation of the three keywords geographic information sciences, cartography and geo-visualization, is the path to the confrontation of the space-time relationship and the usability of users in the creation of cognitive subsidies to planning the territory.

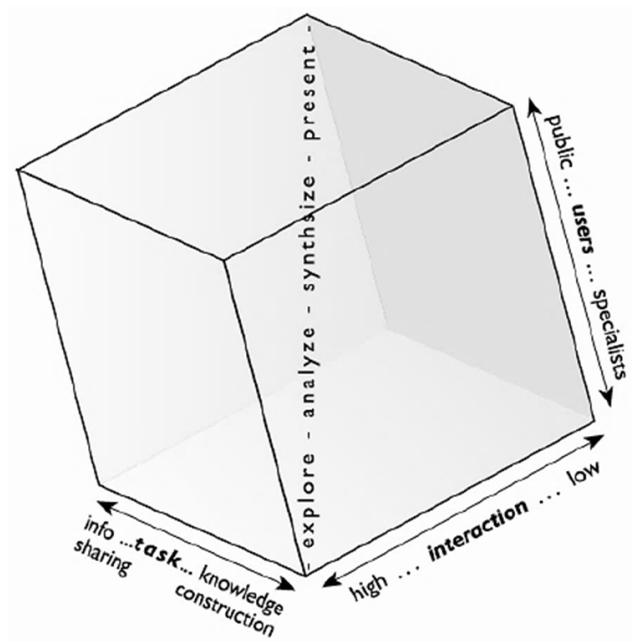

Figure 2: The four functions of visualization (MacEachren, 2004, p.01)

In addition, Geogame is a method and instrument with a focus on the virtual and / or physical exploration of the territory, based on geodata, for the incorporation of elements of fun, intuition, and engagement in tackling the problematic of playful, narrative and performative co-design (Schlieder, 2014). According to Schlieder (2005, p.168), not all games that encompass location are considered geogames, and, more important, if the game does not satisfy a binomial space-time relationship, which is prized in geo-visualization studies, it is also not a geogame.

In sum, it is proposed to articulate Geodesign, Geovisualization and Geogames applied to territorial planning, in order to provide citizens who participate in the process of knowledge construction and spatial awareness through geovisualization and interaction with data and dynamic maps. The central idea of the is the 3 G's is to develop intuitive perception through the exploration and manipulation of geovisual data, and apply a multicriteria analysis with the production of several possible scenarios for the project intervention. Table 1 presents the articulation between the 3 G's, focusing on the first three Geodesign models, which refers to the preparation of the public participation for the Geodesign workshop, and are the basis for structuring the Geodesign Gamification Methodological Roadmap in the next item.

Table 1: 3G's: Geodesign, Geovisualization and Geogames

\begin{tabular}{|c|c|c|}
\hline Geodesign & Geovisualização & \multicolumn{2}{c|}{ Geogames } \\
\hline Representation & Inform & Preparatory Games \\
\hline Process & Explore & Exploratory Games \\
\hline Evaluation & Analyze & Evaluation Games \\
\hline
\end{tabular}




\section{Methodological Guide for the Gamification of Geodesign}

This item presents a study about the elaboration of a Methodological Guide to be applied with children between the ages of 9 and 13 in the community of Tirol, in the municipality of Santa Leopoldina, State of Espírito Santo, Brazil (Andrade et al, 2016), as a phase that precedes the co-design of selfsustaining development scenarios for the future. The itinerary for the workshop with children is structured by the $3 \mathrm{G}$ 's crossing, focusing on the addition of geogames correlated to 1) information and preparation of children for the workshop Preparatory Games; 2) exploration and virtual navigation of the territory - Exploratory Games; and 3) analysis and evaluation of the representation of the territory - Evaluation Games.

It is important to emphasize the use of the multidisciplinary Design Thinking (mDT) as a methodological procedure for modeling the geogames used in Minecraft for the participation of children in the preparation of the Geodesign workshop. Tellioglu (2016a) explains that mDT is a version of Design Thinking that stands out as an interactive, user-centered multidisciplinary approach to support creativity and innovation. MDT not only demonstrates how to design for users, but also how to envolve and engage them during the totality of the design process. It is a combination of a variety of design methods, which involves, for example, creating the idea, defining design parameters and formats, until the exact configuration and description of design system properties, which must then be constructed. Among the several methods present in mDT (Tellioglu, 2016b), based on design-evaluateredesign logic, the focus goes toward the Design Games phase for this article.

The structuring sequence of the Methodological Guide follows:

\section{Preparatory Games:}

1.1 Decision on Territorial Systems based on survey to elaborate a wordcloud. Children write paragraph about territorial values. All words are typed into a text file, and a wordcloud (Figure 3 ) is automatically drawn from the words that most often repeat between children's descriptions.



Figure 3: Wordcloud of Children's heritage values in Tirol in Brazil.
1.2 Elaboration of five Territorial Systems in a GIS software, covering a survey and construction of data. The five systems defined from the children's wordcloud are: Environmental Heritage (Vegetation, rivers, mountain), Territorial Heritage (Church, School, houses), Socioeconomic Heritage (Plantations, plantations), Ludic Heritage (Playground, game and fun), Infrastructural Heritage (Roads, mobility, accessibility). The binomial used to name the systems is based on the Italian Territorialist Theory (Magnaghi, 2010), and its concept of the territory as heritage, addressed to a selfsustaining local development, and civic participation throughout planning and management processes, as well as reviewing territorial parametric laws.

1.3 Transposition of the five systems in five design models in the mDT-based Minecraft, as a fun way to acquire design ideas. Children must model a description of the current territorial context of Tirol in Brazil(Figure 4), and modeling five images of the current context of Tyrol in Austria, imbuing in this moment good practices and articulation with heritage values in order to overcome the dichotomy conservation and development. Children take home the tenth images, each in A5 printed form, designs and models for home, to discuss with parents the similarities and differences between the two cases in Brazil and Austria.

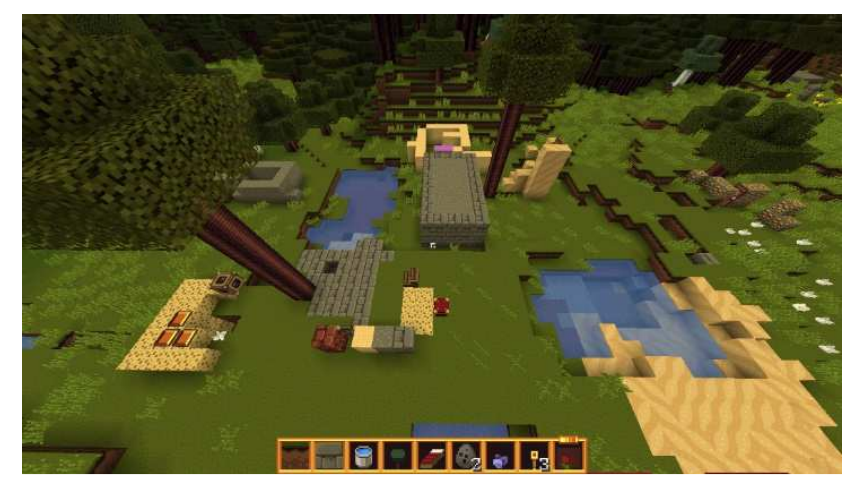

Figure 4: Elaboration of designs in Minecraft (de Andrade et al, 2016, p.831)

\section{Exploratory Games:}

2.1 Virtual Navigation Minigame (VN) of the territory. The NV (Figure 5) is constructed from sets of photographs and panoramas, assembled in a way to promote the effect of being present in the landscape scene. In this way, the user is informed of which points in the map a location is seen, and is able to get the visual range navigating virtually in photographic sets captured from those points. In the VR Worx program, aimed to the elaboration of multimedia products, the panoramas were assembled of a combination of photographs mosaics. An automatic snap-in of the photos is performed to generate the panoramas, by comparing pixel arrays and choosing more suitable overlays, allowing also manual adjustments (Moura, 2009, p.140-141). In addition, the Unity game development platform will be used as NV's gamification tool, facilitating the player to change the landscape, designing 
for example more vegetation areas, or built areas, or asphalting streets, or public spaces, and so on.

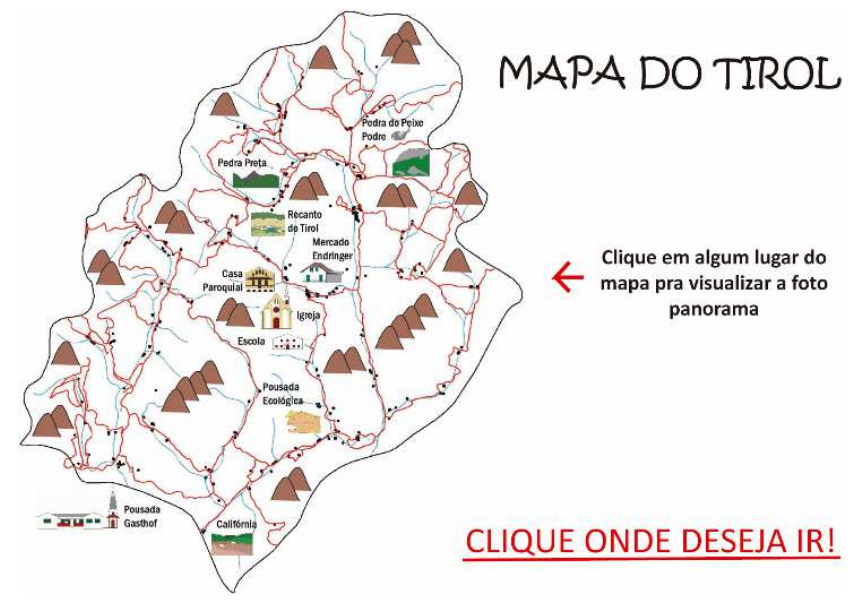

Figure 5: Virtual Navigation of Tirol

2.2 Preparation the kids for the Geodesign workshop with the Geodesign Hub online platform, through the use of virtual three-dimensional exploration of Tirol using Minecraft. The objective is the co-design representations of the territory correlated to each of the five systems presented previously, using the logic block by block of Minecraft, and the knowledge of heritage values and shared codes learned during the previous stage in the interaction between children and parents with images from Brazil and Austria.

\section{Evaluation Games:}

3.1 Card Game Minigame. Consensus maximization reach test using images from the designs developed in the previous step in Minecraft. The images will be organized in A5 format, and in the logic of a card game, five groups of children will represent each five diferente social actors, in order to present and defend opinions about the current territorial context and decide which project to be carried out in the end.

3.2 Evaluation of the mechanical performance of geogames will be performed according to heuristic criteria based on Schlieder (2004) and Ahlqvist et al (2010), and the participatory performance evaluation of children will be performed according to Participatory Cube criteria (Poplin et al, 2013). The Participatory Cube consists of three axes: interactive communication, access to participation space, and decision-making power.

The contribution of mDT to the creation of geogames is addressed to increase children's engagement and, especially to provide a new perceptive dimension of immersion in the territory through digital playful platforms. With centrality in the fun aspect as a postulate for the sequence of activities of the Evaluation phase of Geodesign, contributing decisively in the stage of the Preparatory Games. And the gamification aspect of the interaction between children and parents with images of the territory in Brazil and Austria, by using the cards with the images as elements of game. In the Exploratory Games stage, experiment is addressed to co-design possible changes in the landscape in virtual environment, changing the urban parameters, to materialize ideas from child-parent interaction interaction. And, finally, in the stage of Evaluation Games, it will be possible, through the representations developed among the children, to understand the dynamics with the participatory cube method evaluation. The aim is to evaluate the state of heritage values that children bring, and those acquired during the process, in order to fulfill the proposal of this article, to articulate the 3 G's to co-design the future, and support learning and designing skills in children.

\section{Results \& Discussions}

The expected results are to contribute in the state of the art on Geodesign Studies applied to urban and territorial planning, contributing to innovate through geogames merged with techniques of civic participation. And also for cognitive development in children as co-planners, both proving the relevance of the children's contribution to the preparation of planning processes, as well as visualization and childcomputer interaction aspects, with the articulation of Geodesign and Minecraft. For example, a geogame can be evaluated by mapping the different geographic footprints of the players across their exporation of the territory, in order to understand their choices and its relation to urban design.

The Methodological Guide, developed from the articulation between the $3 \mathrm{G}$ 's, contributes to reflect critically on some issues of approaching Geodesign to territorial planning, such as the ones related to lack of understanding of GIS mapping and civic engagement during the workshop process. As an outcome it is suggested the addition of new elements to the Geodesign methodological process, such as geovisualization and geogames. Moreover, design thinking has a singular influence in placing children's values at the center of the design process, and in offering a complete design model process that strengthen and expand their mental maps of the territory, as well as interacte with other actors in society such as experts and family members.

The next phase of the present research is the continuity of the Methodological Guide related to the Geodesign Intervention phase, which includes the three following models: Change, Impact and Decision. And gather knowledge to elaborate an original game in Unity game builder (2D and/or 3D), with emphasis on gamification of the Geodesign Hub. The aim is to transpose previous games in Unity, and create a whole game system that interfaces with the Geodesign Hub helping with elements of fun, geo-visualization, and consensus-building. Furthermore, includes work on the possibility of making the game online and collaborative, to be accessed from anywhere and enable real-time communication between the technical team, the participants, and other actors of the society involved, specially targeting children in Brazil and Austria to collaborate. For the process of construction of the original geogame in Unity it will be used the method of Schlieder (2014) (Figure 6), alongside with the Design Games phase of the mDT (Tellioglu, 2016b). 




Figure 6: Process of a geogame design (Schlieder, 2014)

\section{Acknowledgents}

We acknowledge for making the development of this research the Post-Graduate Program in Architecture and Urbanism at the Federal University of Minas Gerais, Brazil; the Coordination for the Improvement of Higher Education Personnel (CAPES) and the National Council for Scientific and Technological Development (CNPq); and specially the Erasmus Mundus Smart ${ }^{2}$ Project: SmartCities \& SmartGrids for Sustainable Development, and the Institute of Design and Assessment of Technology at the Vienna University of Technology, Austria;

\section{References}

Ahlqvist, O., Benkar, R., Mikula, B., \& Vatev, K. (2014). Online Map Games-playful interaction with complex real-world issues. In AGILE conference on geographic information science, Castellon (Vol. 3).

Andrade, B. A. de, de Sena, Í. S., \& Moura, A. C. M. (2016). Tirolcraft: The Quest of Children to Playing the Role of Planners at a Heritage Protected Town. Progress in Cultural Heritage: Documentation, Preservation, and Protection. Proceedings, Part I (pp. 825-835). Cham: Springer International Publishing. https://doi.org/10.1007/978-3-319-48496-9_66.

Andrade, B. A. de, \& Moura, A. C. M. (2016) Leg godt: Lego 3D for children to design a new playground for Tirol in Brazil. Presentation at FROG2016 - Future and Reality Of Gaming. Beyond Gameplay - Game Cultures andGgame Practices.

Andrienko, G., Andrienko, N, Jankowski, P, Keim, D, Kraak, M-J, MacEachren, A, \& Wrobel, S. (2007). Geovisual Analytics for Spatial Decision Support: Setting the Research Agenda. International Journal of Geographical Information Science 21, 8, 839-857.

Andrienko, G., Andrienko, N., Keim, D., MacEachren, A. M., \& Wrobel, S. (2011). Challenging problems of geospatial visual analytics. Academic Press.

Banerjee, I., \& Fischer-Schrieber, I. (2015). Digital Communities 2004 - 2014. Selected Projects from Prix Ars Electronica. Viena: Ars
Electronica. Retrieved from https://www.aec.at/postcity/files/2015/09/ARS_digitalcommunities _2004_2014.pdf.

Goldstone, W. (2009). Unity game development essentials. Packt Publishing Ltd.

MacEachren, A. M., Gahegan, M., Pike, W., Brewer, I., Cai, G., Lengerich, E., \& Hardistry, F. (2004). Geovisualization for knowledge construction and decision support. IEEE Computer Graphics and Applications, 24(1), 13-17.

Magnaghi, A. (2010). II progetto locale. Florença: Bollati Boringhieri.

Paba, G., Pecoriello, A. L., Perrone, C., \& Rispoli, F. (2009). Partecipazione in Toscana. Interpretazioni e racconti (Vol. 82). Firenze University Press.

Schlieder, C. (2014). Geogames - Gestaltungsaufgaben und geoinformatische Lösungsansätze. Informatik-Spektrum, 37(6), 567-574. https://doi.org/10.1007/s00287-014-0826-0.

Schlieder, C., Kiefer, P., \& Matyas, S. (2005). Geogames: A Conceptual Framework and Tool for the Design of Location-Based Games from Classic Board Games. Intelligent Technologies for Interactive Entertainment. Proceedings (pp. 164-173). Berlin, Heidelberg: Springer Berlin Heidelberg. https://doi.org/10.1007/11590323_17.

Moura, A. C. M. (2014). Geoprocessamento na gestão e planejamento urbano. 3 ed. Rio de Janeiro: Interciência.

Poplin, A. (2012). Playful public participation in urban planning: A case study for online serious games. Computers, Environment and Urban Systems, 36(3), 195-206.

Poplin, A., Pereira, G. C., \& Rocha, M. C. F. (2013). The Participatory Cube: A Framework for Analysis of Online Participation Platforms. Planning Support Systems for Sustainable Urban Development (pp. 395-414). Berlin, Heidelberg: Springer Berlin Heidelberg. https://doi.org/10.1007/978-3-642-37533-0_23.

Rowe, G., \& Frewer, L. J. (2004). Evaluating public-participation exercises: a research agenda. Science, Technology, \& Human Values, 29(4), 512-556.

Steinitz, Carl. Um framework para o Geodesign. Alterando a Geografia através do design. Esri Press, 2016.

Tellioglu, H. (2016a). Models as Bridges from Design Thinking to Engineering. Proceedings of the 10th International Conference on Interfaces and Human Computer Interaction (IHCl) 2016, in Multi Conference on Computer Science and Information Systems, July 1-4, Funchal, Madeira, Portugal. Best Paper Award

Tellioglu, H. (2016b). The Role of Design Models in Design Thinking. IADIS International Journal on Computer Science and Information Systems, 11(2), pp. 132-145. ISSN: 1646-3692

Zyngier, Camila Marques. "Paisagens Urbanas Possíveis: Códigos Compartilhados Através dos Sistemas de Suporte ao Planejamento e do Geodesign." Universidade Federal de Minas Gerais, 2016. 